\title{
Shear Velocities and Elastic Parameters of the Mantle ${ }^{1}$
}

\author{
Don L. Anderson and Bruce R. Julian \\ Seismological Laboratory, California Institute of Technology \\ Pasadena, California 91109
}

\begin{abstract}
The recent shear wave travel-time data of Ibrahim and Nuttli (1967) and Doyle and Hales (1967) is reinterpreted to yield a shear-velocity structure that is compatible with Johnson's (1967) compressional-velocity structure. The elastic parameters $\Phi, K / \mu$, and $\sigma$ are calculated as a function of depth. All three parameter increase with depth in the homogeneous regions of the mantle but only $\Phi$ increases through the transition regions. Poisson's ratio is apparently less for the close-packed deeper mantle phases than it is for the normal phases of the upper mantle. The theoretical prediction that $d \mu / d P$ becomes negative before a phase change is verified by the seismic data.
\end{abstract}

\section{INTRODUCTION}

Much effort has been spent in the last few years in the collection and analysis of compressional velocity data and in the inversion of this data to obtain compressional velocity structures. The travel time, apparent velocity, and amplitude curves have been found to be very complicated out to about $40^{\circ}$, and they are obviously the result of more than one branch being involved. The complications are caused by regions of abnormally high-velocity gradients in the upper mantle [Niazi and Anderson, 1965; Johnson, 1967; Kanamori, 1967; Jutian and Anderson, 1968; Green and Hales, 1968; Lewis and Meyer, 1968; and Archambeau et al., 1969] that had previously been found by surface wave studies [Anderson and Toksoz, 1963]. A detailed interpretation of these high velocity gradients in terms of phase changes was given in Anderson [1967].

The only comparable study for $S$ waves is that of Ibrahim and Nuttli [1967]. Using polarization techniques to identify the shear arrivals, they determined travel-time curves out to about $50^{\circ}$ for focal depths of 33 and 120 $\mathrm{km}$. The travel time curves were similar in their complexity to the $P$ travel-time curves. Much of their data was pertinent to western North

\footnotetext{
Contribution No. 1615, Division of Geological Sciences, California Institute of Technology, Pasadena.
}

Copyright @ 1969 by the American Geophysical Union.
America, a region studied intensively by Niazi and Anderson [1965], Johnson [1967], Julian. and Anderson [1968], and Archambeau et al. [1969] with $P$ waves. Ibrahim and Nuttli [1967] determined a shear velocity structure that gave very good agreement with their data for both focal depths. Although their model was in gross agreement with the recent $P$ structures in that it had a pronounced upper mantle lowvelocity zone and discontinuities near 400 and $700 \mathrm{~km}$, it differed in some important details. The main differences in the models are the depths to the low-velocity zone and to the discontinuity between 600 and $750 \mathrm{~km}$. An interesting feature of their model was the existence of large regions of constant velocity.

In another notable recent paper, Doyle and Hales [1967] determined a new shear-velocity travel-time curve between about 28 and $80^{\circ}$.

These papers are important in that they provide a refined travel-time curve for $S$ waves and provide the possibility of improving our estimates of the variation of shear velocity with depth in the mantle. Quite apart from being important in its own right, this improvement is essential in free oscillation interpretations since the shear velocity is the dominant parameter for most of the modes of free oscillation. If this parameter can be determined independently with good precision, then, and only then, the free oscillation data can be used to determine the density distribution in the earth. In addition the shear velocity data can be combined with the compressional velocity data in order to 


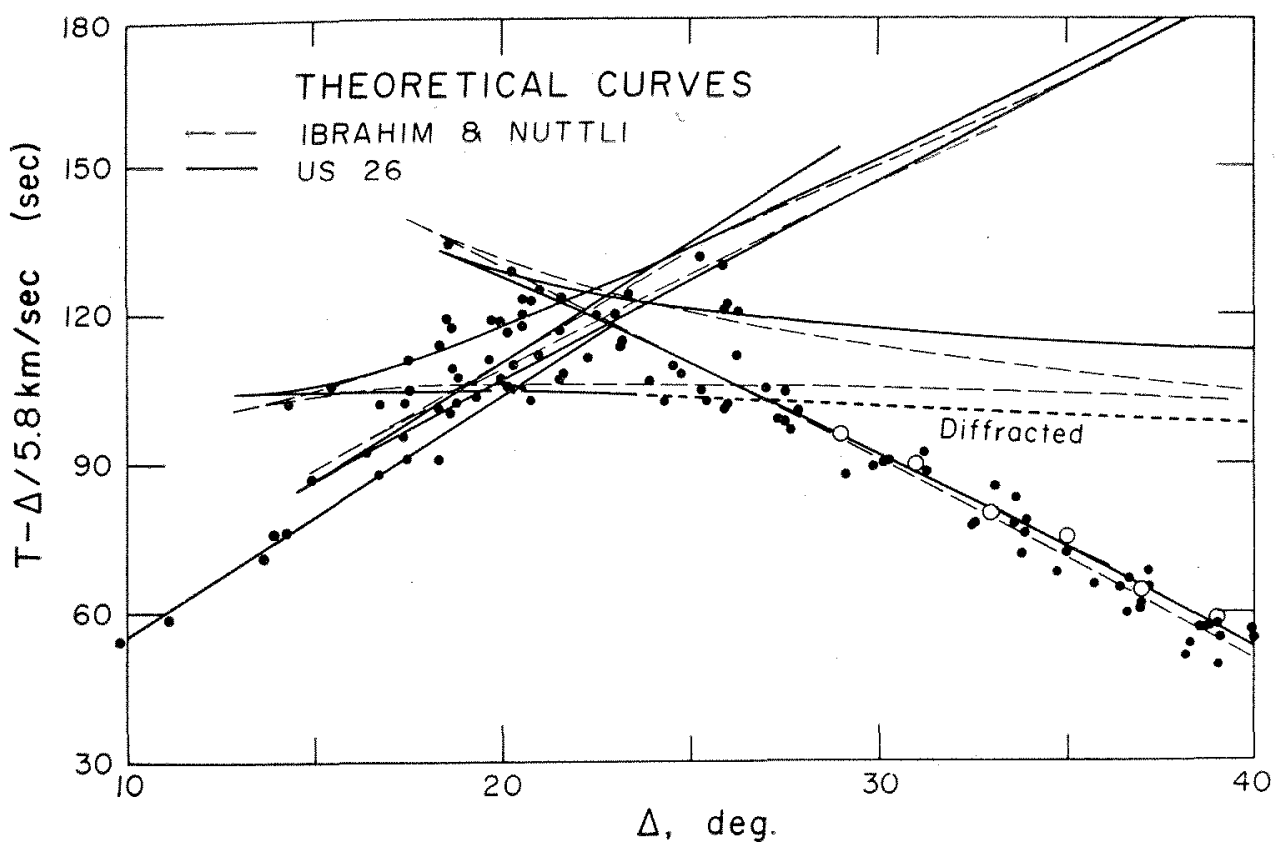

Fig. 1. Reduced travel-time curve for shear waves from shallow focus earthquakes. Depth of focus, $33 \mathrm{~km}$. Data: open circle, Doyle and Hales [1967]; solid dot, Ibrahim and Nuttli [1967].

determine the depth variation of such important parameters as the seismic parameter $\phi$ and and Poisson's ratio $\sigma$. These quantities are involved in the interpretation of seismic data in terms of composition and petrology of the various regions of the mantle.

It is the purpose of this paper to invert this data in such a way that the resulting shearvelocity profile is similar to recent compressional velocity profiles that are based on a much larger body of data. By 'similar' we mean that such features as low-velocity zones and transition regions should occur at roughly the same depth in both profiles. These compatible profiles can then be combined to yield the other parameters noted above. In addition the degree of non-uniqueness of the structures resulting from the inversion of this kind of data is clearly demonstrated. Lateral variations are still a problem in all studies of this type, and studies in different regions are clearly desirable.

\section{Data}

The raw data of Ibrahim and Nuttli [1967] were used and were independently corrected to either $33 \mathrm{~km}$ or $120 \mathrm{~km}$, depending on whether the earthquake was shallow or intermediate. The first arrival data beyond $28^{\circ}$ was taken from Doyle and Hales [1967] and was corrected to $33 \mathrm{~km}$ by taking their tabulated J-B residuals and applying the correction to the J-B tables. Figure 1 shows that the two sets of data are compatible although the scatter is substantial.

\section{Analysis and Results}

The inversion was accomplished by trial and error using the travel-time program TVT3 described by Julian and Anderson [1968]. Johnson's [1967] $P$-wave model CIT204 was used as a guide, and we attempted to have the locations and thicknesses of the low-velocity zone and the transition regions be the same as in this model.

Figures 1, 2, and 3 show the fit of the IbrahimNuttli model and our model, US26. Both models fit the data out to $40^{\circ}$ about equally well.

The models are shown in Figure 4. By introducing negative gradients for shear waves where Ibrahim and Nuttli [1967] had constant ve- 


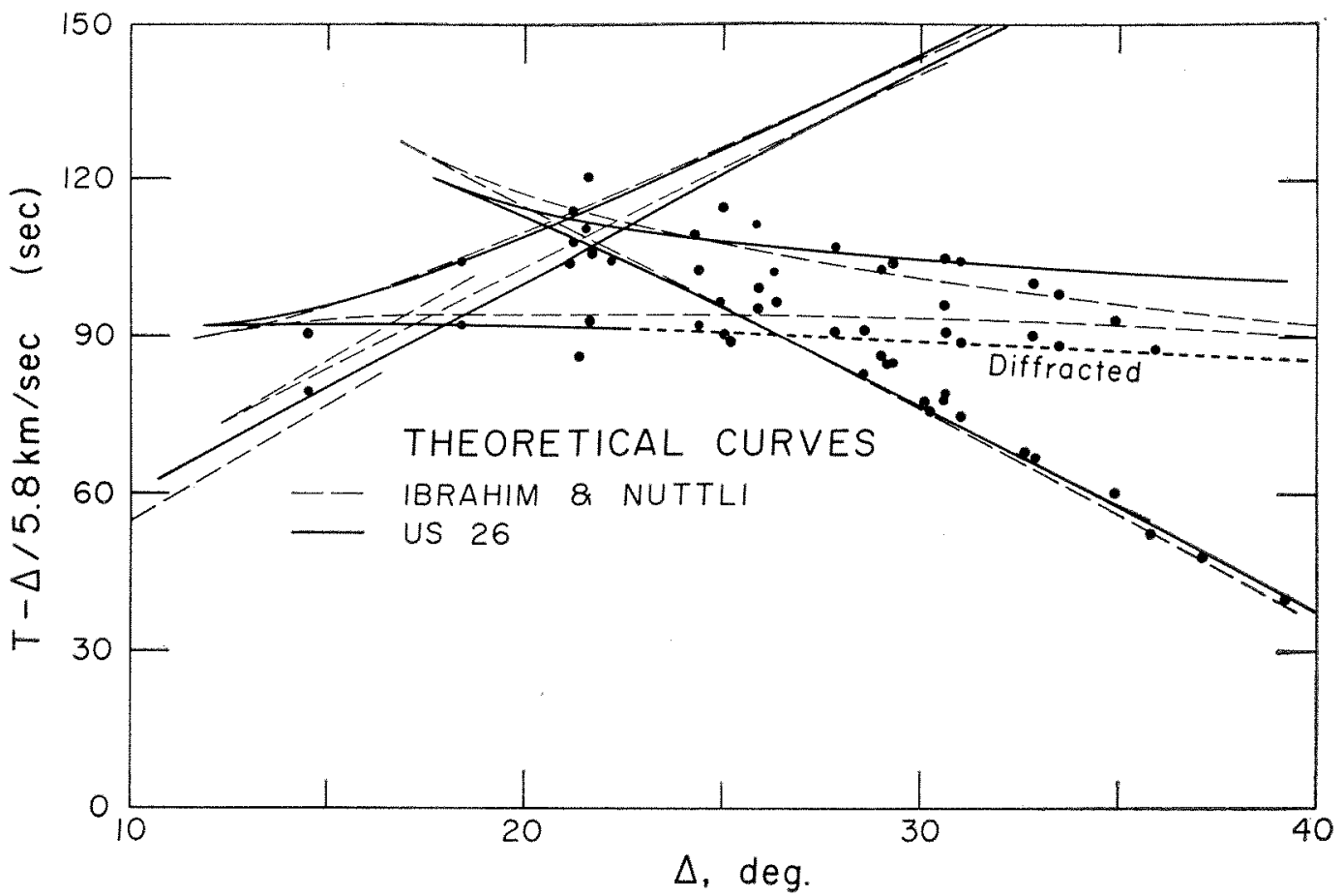

Fig. 2. Reduced travel-time curve for shear waves from intermediate focus earthquakes. Depth of focus, $120 \mathrm{~km}$; data from Ibrahim and Nuttli [1967].

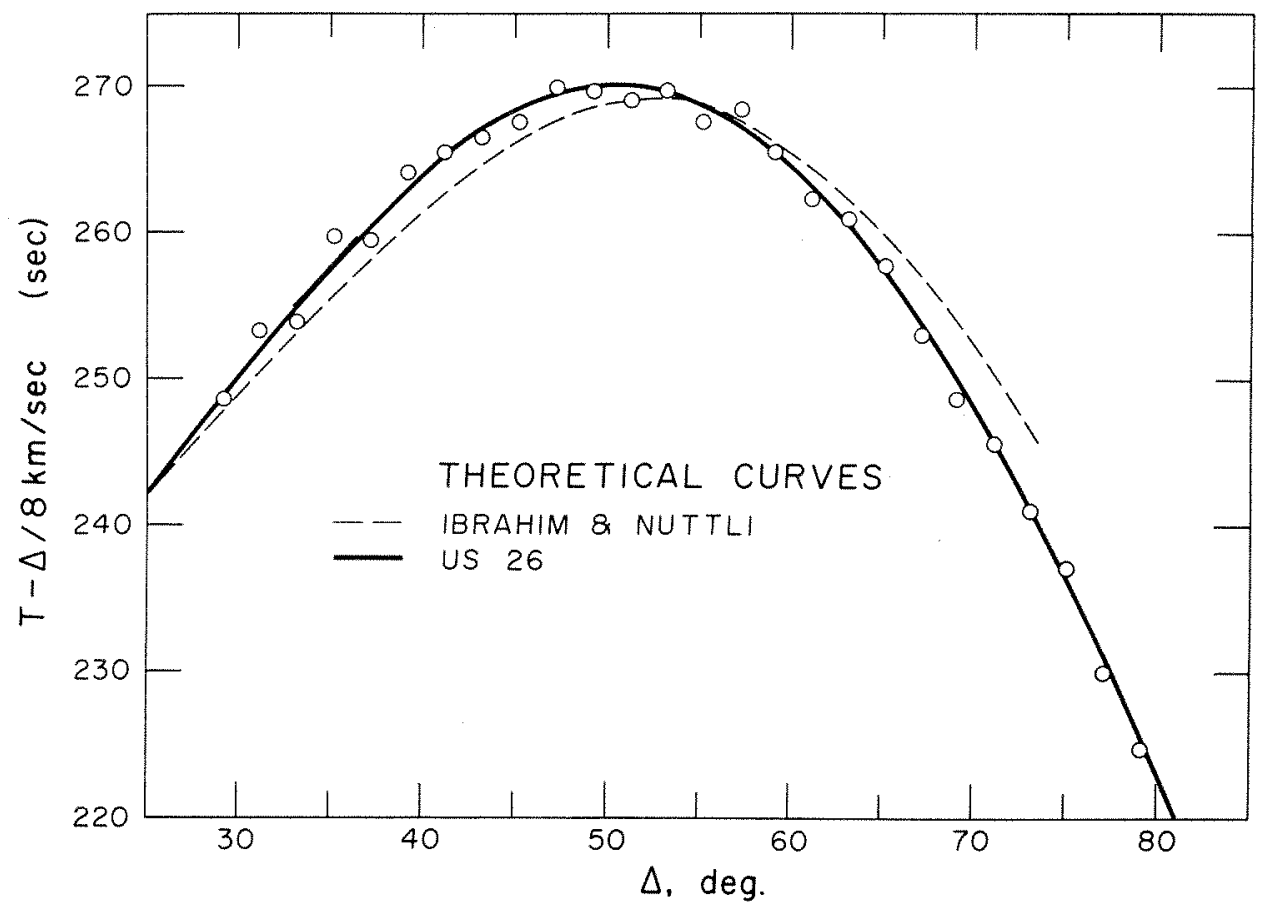

Fig. 3. Reduced travel-time curve for shear waves between $25^{\circ}$ and $80^{\circ}$. Depth of focus, 33 $\mathrm{km}$; data from Doyle and Hales [1967]. 


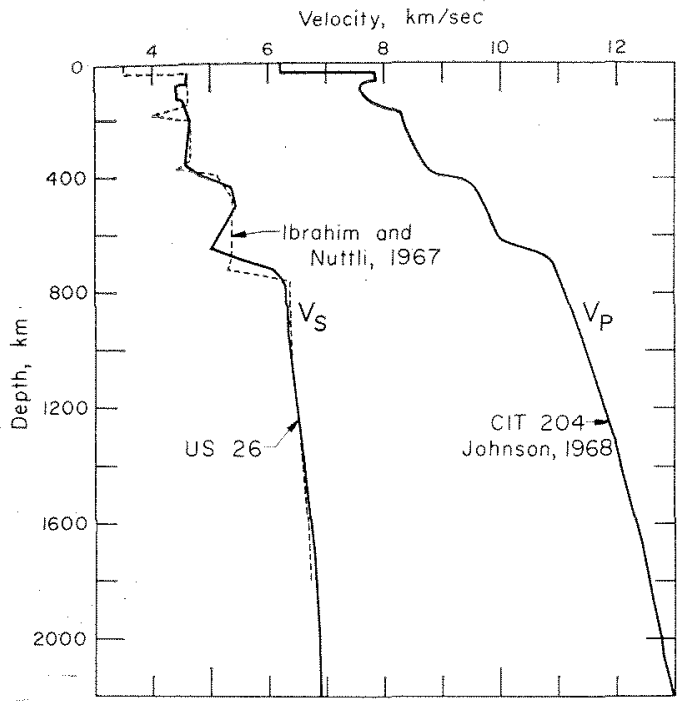

Fig. 4. Shear velocity model of Ibrahim and Nutti [1967] and present work and compressional velocity model of Johnson [1967]. locity gradients, it has been possible to find a model that is nearly compatible with the compressional velocity model. As expected from the nature of travel-time data the two shearvelocity solutions oscillate about each other. The large negative gradient between 500 and $650 \mathrm{~km}$ in US26 prevents any ray from bottoming in this region; the corresponding branch of the travel-time curve for this model therefore represents diffracted energy (see Figures 1 and 2). The negative velocity gradients above $400 \mathrm{~km}$ can easily be explained by a modest $\left(\sim 5^{\circ} \mathrm{C} / \mathrm{km}\right)$ temperature gradient that, for shear waves, cancels out the effect of pressure in increasing the velocity. The large negative gradient between 500 and $650 \mathrm{~km}$, however, requires that the material in this region, presumably mainly olivine in the spinel structure, have a low $\left(\partial V_{\mathcal{S}} / \partial P\right)_{r}$ or a high $\left(\partial V_{S} / \partial T\right)_{P}$ or both. There is, of course, a large uncertainty in the actual gradient.

TABLE 1. Velocities and Elastic Parameters as Function of Depth

\begin{tabular}{rccccccccc}
\hline $\begin{array}{c}\text { Depth, } \\
\mathrm{km}\end{array}$ & $\begin{array}{c}V_{S_{2}}{ }^{*} \mathrm{sm} \\
\mathrm{km} / \mathrm{sec}\end{array}$ & $\begin{array}{c}V_{S_{2}},{ }^{*} \\
\mathrm{~km} / \mathrm{sec}\end{array}$ & $\begin{array}{c}V_{P}{ }^{* *} \\
\mathrm{~km} / \mathrm{sec}\end{array}$ & $\begin{array}{c}\Phi_{1}, \\
(\mathrm{~km} / \mathrm{sec})^{2}\end{array}$ & $\begin{array}{c}\Phi_{2,} \\
(\mathrm{~km} / \mathrm{sec})^{2}\end{array}$ & $(\mathrm{~K} / \mu)_{2}$ & $(\mathrm{~K} / \mu)_{2}$ & $\sigma_{1}$ & $\sigma_{2}$ \\
\hline 35 & 4.60 & 4.60 & 7.85 & 33.4 & 33.4 & 1.58 & 1.58 & 0.238 & 0.238 \\
50 & 4.60 & 4.59 & 7.87 & 33.7 & 33.8 & 1.59 & 1.61 & 0.240 & 0.242 \\
65 & 4.60 & 4.59 & 7.70 & $(31.1)$ & $(31.2)$ & $(1.47)$ & $(1.48)$ & $(0.222)$ & $(0.224)$ \\
80 & 4.60 & 4.40 & 7.60 & $(29.5)$ & 31.9 & $(1.40)$ & 1.65 & $(0.211)$ & 0.248 \\
100 & 4.60 & 4.40 & 7.61 & $(29.7)$ & 32.1 & $(1.40)$ & 1.66 & $(0.212)$ & 0.249 \\
125 & 4.60 & 4.40 & 7.70 & $(31.1)$ & $(33.5)$ & $(1.47)$ & $(1.73)$ & $(0.222)$ & $(0.258)$ \\
150 & 4.53 & 4.55 & 7.93 & $(35.5)$ & $(35.3)$ & $(1.73)$ & $(1.70)$ & $(0.258)$ & $(0.255)$ \\
180 & 4.00 & 4.60 & 8.30 & $(47.6)$ & 40.7 & $(2.97)$ & 1.92 & $(0.349)$ & 0.278 \\
200 & 4.60 & 4.64 & 8.31 & $(40.8)$ & $(40.3)$ & $(1.93)$ & $(1.87)$ & $(0.279)$ & $(0.273)$ \\
250 & 4.65 & 4.60 & 8.42 & 42.1 & 42.7 & 1.94 & 2.02 & 0.281 & 0.287 \\
300 & 4.65 & 4.58 & 8.54 & $(44.1)$ & 45.0 & $(2.04)$ & 2.14 & $(0.289)$ & 0.298 \\
350 & 4.57 & 4.55 & 8.67 & $(47.3)$ & $(47.6)$ & $(2.27)$ & $(2.30)$ & $(0.308)$ & $(0.310)$ \\
400 & 5.13 & 4.90 & 9.30 & 51.4 & $(54.5)$ & 1.95 & $(2.27)$ & 0.281 & $(0.308)$ \\
450 & 5.30 & 5.39 & 9.63 & 55.3 & 54.0 & 1.97 & 1.86 & 0.283 & 0.272 \\
500 & 5.37 & 5.44 & 9.75 & 56.6 & 55.6 & 1.96 & 1.88 & 0.282 & 0.274 \\
550 & 5.37 & 5.29 & 9.84 & $(58.4)$ & 59.5 & $(2.02)$ & 2.13 & $(0.288)$ & 0.297 \\
600 & 5.37 & 5.15 & 9.95 & $(60.5)$ & $(63.6)$ & $(2.10)$ & $(2.40)$ & $(0.294)$ & $(0.317)$ \\
650 & 5.37 & 5.00 & 10.55 & $(72.8)$ & $(78.7)$ & $(2.53)$ & $(3.12)$ & $(0.325)$ & $(0.355)$ \\
700 & 5.33 & 5.75 & 10.95 & $(82.0)$ & $(75.8)$ & $(2.89)$ & $(2.29)$ & $(0.345)$ & $(0.310)$ \\
750 & 6.14 & 6.23 & 11.03 & 71.4 & $(69.9)$ & 1.89 & $(1.80)$ & 0.275 & $(0.266)$ \\
800 & 6.38 & 6.30 & 11.11 & 69.2 & 70.5 & 1.70 & 1.78 & 0.254 & 0.263 \\
900 & 6.38 & 6.33 & 11.30 & $(73.4)$ & 74.3 & $(1.80)$ & 1.85 & $(0.266)$ & 0.271 \\
1000 & 6.40 & 6.38 & 11.47 & 76.9 & 77.3 & 1.88 & 1.90 & 0.274 & 0.276 \\
1200 & 6.49 & 6.51 & 11.80 & 83.1 & 82.7 & 1.97 & 1.95 & 0.283 & 0.281 \\
1400 & 6.60 & 6.63 & 12.08 & 87.8 & 87.3 & 2.02 & 1.99 & 0.287 & 0.284 \\
1600 & 6.68 & 6.74 & 12.34 & 92.8 & 91.7 & 2.09 & 2.02 & 0.293 & 0.287 \\
1800 & 6.73 & 6.83 & 12.55 & 97.1 & 95.3 & 2.14 & 2.04 & 0.298 & 0.290 \\
& & & & & & & & & \\
\hline
\end{tabular}

* Subscript 1 refers to Ibrahim and Nuttli structure; subscript 2 is US26.

** CIT204 [Johnson, 1967]. 
The shear-velocity structures obtained by Ibrahim and Nuttli [1967] and reported in this paper are tabulated in columns 2 and 3 of Table 1. These are combined with Johnson's model CT204 (column 4) to obtain the elastic parameters in the remaining columns. No attempt has been made to smooth the results. Values in parentheses are in transition regions or represent regions where the shear velocity model is incompatible with the compressional velocity model. If these values are ignored, there is a relatively uniform increase of $\phi$ with depth as shown in Figure 5, except for the low-velocity zone that has a lower $\phi$ than the adjacent regions of the mantle. $K / \mu$ and $\sigma$ increase rather uniformly with depth to at least $300 \mathrm{~km}$. The values for these parameters are less in the region between the major discontinuities, i.e. the 'spinel' section of the mantle, than at 300 $\mathrm{km}$, but increase with depth in this region. These values drop again in going through the $650 \mathrm{~km}$ phase change and increase relatively slowly thereafter. The general tendency is for the Poisson's ratio to increase with depth in relatively homogeneous regions of the mantle. This increase is to be expected since both temperature and pressure increase Poisson's ratio. The

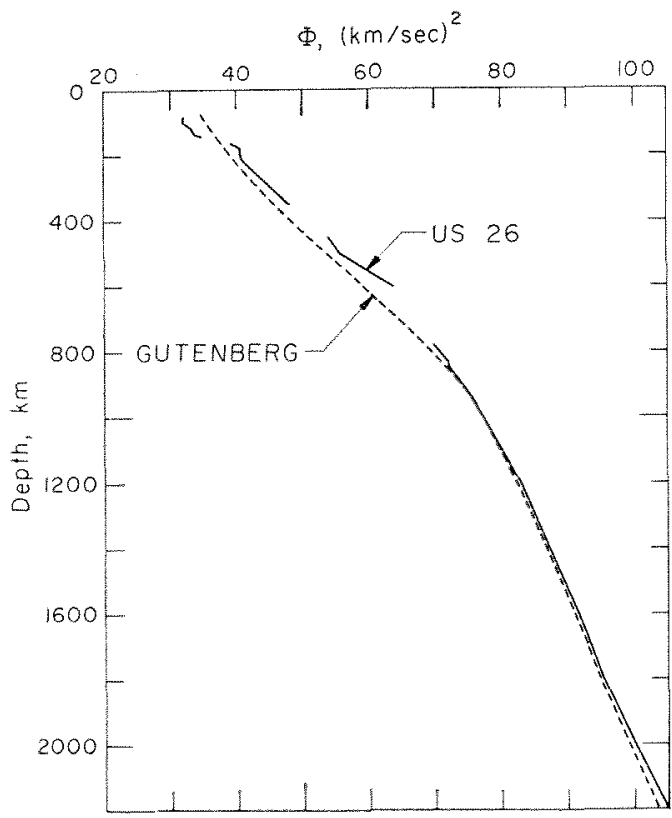

Fig. 5. Seismic parameter $\Phi$ versus depth in the homogeneous regions of US26 compared with the Gutenberg model.
TABLE 2. Properties of Simple Oxides

\begin{tabular}{llllll} 
Substance Coordination & $\langle M\rangle$ & $\rho_{0}$ & P.I. & $\sigma^{\mathbf{l}}$ \\
\hline $\mathrm{BeO}$ & $4-4$ & 12.5 & 3.00 & 7.2 & .205 \\
$\mathrm{ZnO}$ & $4-4$ & 40.7 & 5.62 & 5.3 & .357 \\
$\mathrm{Al}_{2} \mathrm{O}_{3}$ & $6-4$ & 20.4 & 3.97 & 7.2 & .236 \\
$\mathrm{Fe}_{2} \mathrm{O}_{3}$ & $6-4$ & 31.9 & 5.25 & 6.6 & .308 \\
$\mathrm{MgO}$ & $6-6$ & 20.2 & 3.58 & 6.3 & .182 \\
$\mathrm{CaO}$ & $6-6$ & 28.0 & 3.29 & 5.3 & .210
\end{tabular}

Anderson et al. [1969]

drop in Poisson's ratio upon passing through the transition regions was unexpected. There is not enough ultrasonic data available to say whether this effect is due to composition or crystal structure. Since most of the increase of veloeity through the transition regions is due to phase changes, most of the drop in Poisson's ratio is probably due to change in crystal structure. If this probability is true, one would predict $\sigma_{1}$ (olivine) $>\sigma_{22}$ (spinel) $>\sigma_{3}$ (postspinel), or $d \sigma_{1} / d Z>d \sigma_{2} / d Z>d \sigma_{3} / d Z$, or both.

Table 2 gives Poisson's ratio for 6 simple oxides. $\langle M\rangle$ is the mean atomic weight, $\rho_{0}$ is the zero-pressure density, and $P . I$. is the packing index of Fairbairn [1963], a measure of how effectively the ions are packed into a unit cell. For a given coordination Poisson's ratio decreases as the packing index increases. For a given mean atomic weight Poisson's ratio decreases as the coordination increases. For the olivine-spinel phase change there is an increase in packing index with no change in coordination while for the spinel-post-spinel phase change there is an increase in both the packing index and the coordination. The seismic data seems consistent, therefore, with the limited amount of pertinent ultrasonic data.

Note added in proof: G. Barsch and O. L. Anderson (personal communications) have suggested that a negative $d \mu / d P$ implies an unstable crystal lattice. It follows that the shear velocity should decrease with depth above each change in the earth's mantle. This is consistent with the interpretations given here and by Ibrahim and Nuttli [1967].

Acknowledgments. This research was supported by the Advanced Research Projects Agency of the Department of Defense and was monitored by the Air Force Office of Scientific 
Research under Contract No. F44620-69-C-0067 and National Science Foundation grant GA 1003. We would like to thank A. Ibrahim, O. Nuttli, A. Hales and H. Doyle for advance copies of their manuscripts.

\section{REFERENCES}

Anderson, Don L., Phase changes in the upper mantle, Science, 15\%, 1165-1173, 1967.

Anderson, Don L., and M. N. Toksoz, Surface waves on a spherical Earth, 1, Upper mantle structure from Love waves, $J$. Geophys. Res., 68, 3483-3500, 1963.

Anderson, O. L., E. Schreiber, R. C. Liebermann, and N. Soga, Some elastic constant data on minerals relevant to geophysics, Rev. Geophys., 6, 491-524, 1969.

Archambeau, C. B., E. A. Flinn, and D. G. Lambert, Fine structure of the upper mantle, (in press) 1969.

Doyle, H. A., and A. L. Hales, An analysis of the travel times of $S$ waves to North American stations in the distance range $28^{\circ}$ to $82^{\circ}, B u l l$. Seism. Soc. Am., 57, 761-772, 1967.

Fairbairn, H. W., Packing in ionic minerals, Bull. Geol. Soc. Am., 54, 1305-1374, 1943.

Green, R. W. E., and A. L. Hales, The travel times of $P$ waves to $30^{\circ}$ in the central United
States and upper mantle structure, Bull. Seism. Soc. Am., 58, 267, 1968.

Ibrahim, A. K., and O. W. Nuttli, Travel-time curves and upper mantle structure from longperiod $S$ waves, Bull. Seism. Soc. Am. 57, 1063$1092,1967$.

Johnson, L. R., Array measurements of $P$ velocities in the upper mantle, J. Geophys. Res., 7. 6309-6325, 1967.

Julian, B. R., and Don L. Anderson, Travel times, apparent velocities and amplitudes of body waves, Bull. Seism. Soc. Am., 58(1), 339-366, 1968.

Kanamori, H., Upper mantle structure from apparent velocities of $P$ waves recorded at Wakayomo Micro-Earthquake Observatory, Bull. Earthquake Res. Insí., Tokyo Univ., 45, 657$678,1967$.

Lewis, B. T. R., and R. B. Meyer, A seismic investigation of the upper mantle to the west of Lake Superior, Bull. Seism. Soc. Am., 58, 565$596,1968$.

Niazi, M., and Don L. Anderson, Upper mantle structure of western North America from apparent velocities of $P$ waves, $J$. Geophys. Res., $70,4633-4640,1965$.

(Received February 17, 1969 ; revised March 12, 1969.) 